\title{
Modellers deplore 'short-termism' on climate
}

Quirin Schiermeier, Lund

Projections of climate change in, say, Florida or the Alps carry more political weight than vague warnings about global warming. And for almost two decades, specialists in regional climate assessment have sought to make such projections.

But their success has been limited, a meeting of regional-climate modellers in Lund, Sweden, acknowledged last week. Our understanding of regional climate change will remain uncertain, the modellers said. And, some speakers suggested, policymakers' expectations of precise local projections need to be dampened down.

"We're not yet at the promised level where regional climate models can really influence policy-making," Georgios Amanatidis, a scientific officer at the European Commission's research directorate, told the meeting. Participants admitted privately that the immediate benefits of regional climate modelling have been oversold in exercises such as the Clinton administration's US regional climate assessment, which sought to evaluate the impact of climate change on each part of the country.

Most of all, specialists in regional climate change feel that their work, while valuable in the long run, is misunderstood by those in search of immediate results.

"Government and business would like us to predict what will happen in the next 20 years," says Colin Jones, a climate modeller at the Swedish Meteorological and Hydrological Institute in Norrköping. "Unfortunately, we can't - the natural variability of climate makes it next to impossible." The work is most useful for predicting trends beyond 2070, says Jones.

\section{On target}

As the planet heats up, scientists are trying to better understand the impact of global warming on continental, regional and local scales. This extra information could help planners concerned with monsoon regions, mountain areas or coastal zones to develop more targeted adaptation strategies against the adverse effects of climate change.

More powerful computers and better models are improving regional and local climate models, the meeting of 80 experts heard. Researchers are confident that they will generate information that will assist long-term planning in agriculture, flood protection and air-quality management.

The most ambitious regional-climatechange research effort is a European project called Prudence, which is receiving €3.5 million (US\$4.2 million) in European Union funding and will soon develop into a $€ 17$ million programme called Ensembles.

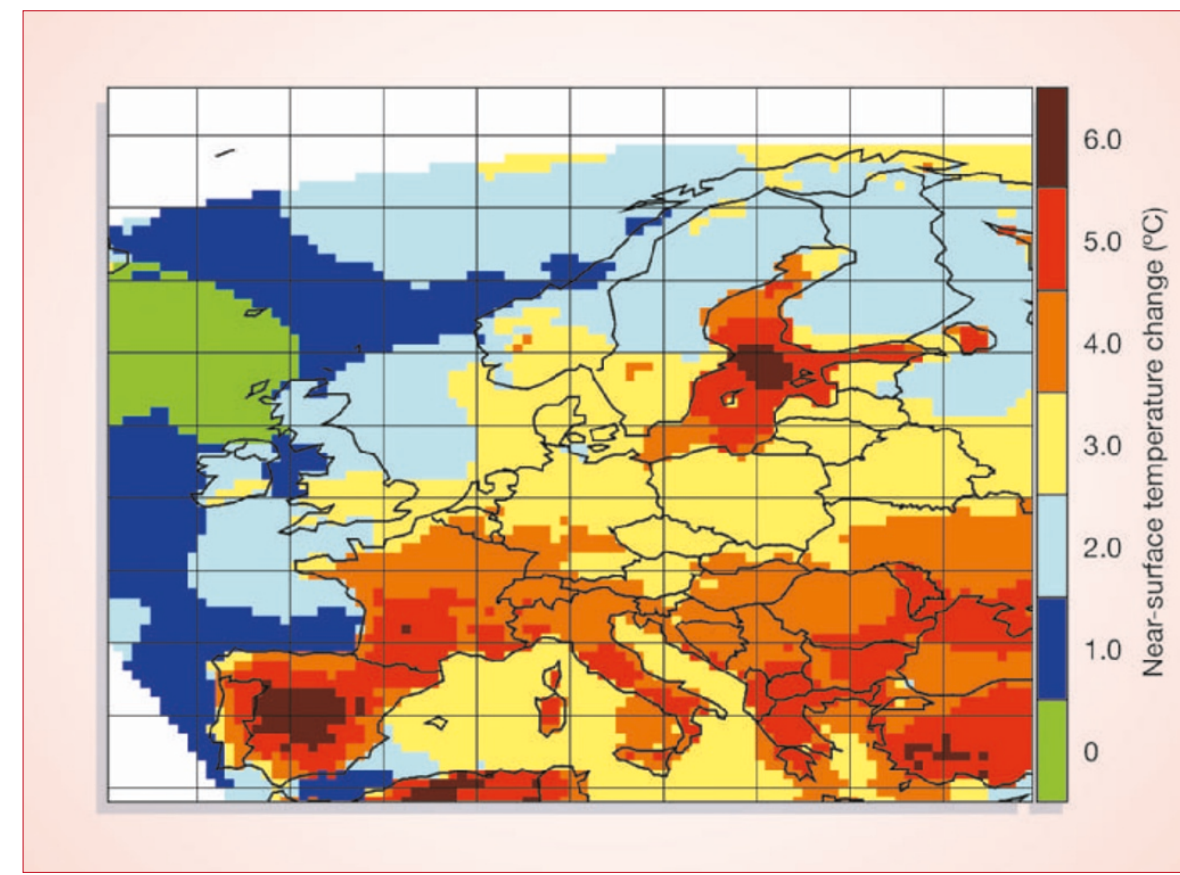

Scientists say that only long-range projections, such as this one for Europe in 2071-2100, count for much.

Prudence uses several models to assess European climate change. Under a pessimistic scenario for greenhouse-gas emissions, its results so far suggest that average temperatures in Europe will rise by $2-8{ }^{\circ} \mathrm{C}$. Warming will be greater in central Europe and the Mediterranean than in the north, Prudence finds; European summers are likely to get drier, although rain heavy enough to cause flooding is likely to become more frequent.

But the size of these changes is uncertain - a message climate modellers say they find difficult to convey. Several participants in Lund said that their community struggles with communicating the stochastic nature of model-based predictions to grant-givers, decision-makers and the public. And many researchers would like to avoid the word 'prediction' altogether.

\section{Regional accent}

Climatologists first tried to track climate signals on a small spatial and temporal scale in 1987, at the US National Center for Atmospheric Research (NCAR) in Boulder, Colorado. They were trying to assess the vulnerability of Yucca Mountain, Nevada, where a nuclear-waste repository is planned, to changes in the water table.

Better computers have increased the use of regional models. "When I left the NCAR in 1997, it took one whole processor of the centre's supercomputer to run a regional simulation - now researchers are doing the same exercise on personal computers," says Filippo Giorgi, an atmospheric physicist now at the Abdus Salam International
Centre for Theoretical Physics in Trieste, Italy.

Giorgi, whom many regard as the founder of regional climate modelling, says he remains convinced of its value. But he does not try to hide the limitations of existing regional climate models.

All high-resolution simulations are based on global climate models. Thus, the weaknesses of the 'mother' models - around ten of which now run globally — rub off on regional simulations, which are based on the same equations representing the thermodynamics of the atmosphere. In regional models, these equations are solved simultaneously for a much larger number of grid points.

"If you don't believe in the value of global climate models then there's no point in downscaling them," says Giorgi. "But if you do - and global models do provide a quite consistent pattern of climate change - then it makes sense to translate global patterns into local information."

Thanks to Prudence, Europe is currently leading the field, Giorgi adds. "There is quite some envy over here of how well things are organized and funded in Europe," says Francis Zwiers, head of the Canadian Centre for Climate Modelling and Analysis in Victoria, British Columbia.

American and Canadian modellers are seeking funds for a similar collaboration of their own. "This would really come at the right time," says René Laprise, principal investigator at the Canadian regional climate modelling group in Montreal, "now that we are finally understanding what we're doing - some of the time!" 